\title{
FREQUENCY OF WRIST GROWTH PLATE INJURY IN YOUNG GYMNASTS AT A TRAINING CENTER
}

\author{
María Roxana Viamont Guerra ${ }^{1}$, Jose Renato Depari Estelles ${ }^{1}$, Yussef Ali Abdouni ${ }^{1}$, Diego Figueira Falcochio ${ }^{1}$, \\ Joao Roberto Polydoro Rosa ${ }^{1}$, Liane Hulle Catanl ${ }^{2}$
}

1. Irmandade da Santa Casa de Misericórdia de São Paulo, Department of Orthopedics and Traumatology, São Paulo, SP, Brazil. 2. Irmandade da Santa Casa de Misericórdia de São Paulo, Department of Pediatrics, São Paulo, SP, Brazil.

\section{ABSTRACT}

Objective: To assess the frequency of physeal injuries and wrist pain in young competitive gymnasts according to their training characteristics. Methods: This is a cross-sectional study (January-June 2015) of a male gymnastics team in São Paulo, SP, Brazil. Nineteen gymnasts, mean age 13.3 years, were evaluated in three ways: a questionnaire, physical examination and radiographs. Results: On average, they trained since 6 years-old and during hours per week. Eighty-two percent had wrist pain and 65\% had wrist physeal injury. The pain was worse in practitioners of (82\%) and soil (17\%) exercises. A greater frequency of physeal injury was found in those with more years of training and higher weekly working hours, wrist pain was more frequent in those with higher weekly working hours, and a decreased range of motion was observed in those with physeal injury, results statistically significant. Conclusions: We found that $65 \%$ of gymnasts had wrist physeal injury and $82 \%$ had wrist pain. There were statistically significant relationships between physeal injury and years of training, physeal injury and weekly working hours, pain and weekly working hours, and physeal injury and range of motion. Level of Evidence IV, Case Series.

Keywords: Athletic Injuries. Child. Adolescent. Wrist.

Citation: Guerra MRV, Estelles JRD, Abdouni YA, Falcochio DF, Rosa JRP, Catani LH. Frequency of wrist growth plate injury in young gymnasts at a training center. Acta Ortop Bras. [online]. 2016;24(4):204-7. Available from URL: http://www.scielo.br/aob.

\section{INTRODUCTION}

The presence of children and adolescents in competitive sports practice has become increasingly frequent. Artistic gymnastics (also known as Olympic gymnastics) is one of the sports where specialization occurs at earlier ages, with intense training to achieve high performance and reach elite levels. Thus, the risk of injury in this population, including specific conditions of the immature skeleton, has become concern of federations, parents, coaches and physicians, requiring greater care in the multidisciplinary approach of these young athletes.

The types of injuries vary according to gender ${ }^{1}$, type of sports modality, training intensity, ${ }^{2}$ age and age of training start, ${ }^{3}$ among others. Injuries can be acute (macrotrauma) or chronic (microtrauma), the latter being strongly associated to overloading and overuse.

The longest duration and intensity of training can lead to overload in the immature skeleton. Chronic wrist pain in young gymnasts is a good example of these conditions, also observed in the distal femur of runners and proximal humerus of baseball pitchers. ${ }^{4}$ The learning curve and gymnast training requires the use of strenuous repetitive movements, which often use the wrist as a loading zone, and forces far exceed their body weight. The wrist is often in dorsiflexion with the stress applied to ulnar and radial deviation movements.

The prevalence of wrist pain in young gymnasts, according to the literature, ranges from 32 to $79 \%$, and $56-67 \%$ in best quality studies..$^{5-8}$ Since the 80 's a relationship between pain and radiographic alterations in young gymnasts' wrist has been observed. ${ }^{9}$ They had mostly pain in the dorsal region of the wrist and the radiographic findings included enlargement of the distal radius growth plate, metaphyseal bone cysts, distal wedging of the epiphysis and blurring of the radiolucent physis area. ${ }^{9}$ At that time, Roy et al. ${ }^{9}$ questioned what would be the future outcome of these changes. Currently, the development of long term positive ulnar variance and bone bar formation in the distal radius physis has been observed, associated with evidence of physeal injury. ${ }^{10}$

Information about the consequences of wrist injuries related to sports practice in young athletes is still limited, as well as its relationship to pain. These children and adolescents often continue their training even with the complaint of pain, risking future serious implications.

All the authors declare that there is no potential conflict of interest referring to this article.

Work developed at Irmandade da Santa Casa de Misericórdia de São Paulo, Department of Orthopedics and Traumatology, Pavilhão Fernandinho Simonsen) and at the Training Center of Artistic Gymnastics, São Caetano do Sul, São Paulo, SP, Brazil 
Despite the sports gesture is similar for all athletes, training rhythm, guidance, and monitoring of these young athletes vary from one population to another.

The objective of this study was to evaluate the frequency of physeal injuries and pain in competitive young gymnasts' wrists and some characteristics of their training in a Brazilian gymnastics training center.

\section{MATERIALS AND METHODS}

A cross-sectional study was conducted to assess the presence of pain and injury of the physis of gymnasts' wrists from a male team at a gymnastics training center in São Paulo, SP, Brazil, between January and June 2015. The study included 19 gymnasts, aged between 9 and 18 years (mean 13.3 years old). Both wrists were evaluated, regardless of pain complaints. Inclusion criteria were practicing competitive sport at national or international level, and the presence of open physis on radiographs. The study excluded athletes who had traumatic injuries associated with upper limb and those who did not have X-rays. The evaluation of the gymnasts was made in three stages. First, a questionnaire was applied to athletes, which included the following items: age of onset of sports practice; years of training; number of hours of weekly training; performed modalities and exercises; presence of wrist pain, duration and intensity (by visual analogue pain scale); restrictions on training due to pain and if there was any reduction in performance.

In the second stage, a physical examination took place, where the following parameters were assessed: pain to palpation, active and passive arc movement including flexion, Extension, radial deviation and ulnar deviation (measured with a goniometer). As a third step of the study, we evaluated the bilateral, anteroposterior and lateral views, and absolute profile of wrists radiographs, in order to evaluate the appearance of the distal physis of the radius and ulna. We considered as signs of injury on the growth plate: enlargement of the distal radial physis, metaphyseal bone cysts, wedging distal epiphysis and blurring of the radiolucent physis area. ${ }^{11}$ The inclination ulnar and volar angle of the radius were also measured.

These data were, then, statistically analyzed by Mann-Whitney test and chi-square test using SPSS V17 software, Minitab 16 and Office Excel 2010. Statistical significance was considered at $p<0.05$.

All study participants or their legal guardians signed a Free and Informed Consent form. The Ethics Committee approval number is CAAE 44941715.5.0000.5479.

\section{RESULTS}

The evaluated gymnasts started their training between 4 and 9 years of age (mean age 6 years old), practicing on average for 7.8 years, training on average 25.7 hours weekly.

The training was conducted continuously in all units of the male artistic gymnastics (floor, pommel horse, jumping table, parallel bars, horizontal bar and rings). All athletes had national and/or international competitive levels.

The prevalence of wrist pain was $82 \%, 53 \%$ bilaterally. Of those who had wrist pain, the average time for the manifestations of pain was 10.9 months and the intensity of pain (VAS) averaged 3.7 points. Among those who complained of wrist pain, $47 \%$ reported that the pain limited their performance during training. The pain was reported during specific modalities in training: horse (82\%), soil
(17\%) and parallel bars (12\%). Only one athlete had to interrupt training for 21 days. On physical examination, the range of motion amplitude is shown in Table 1.

Physis injuries were found in radiographs in $65 \%$ of athletes, $53 \%$ bilaterally. (Figure 1) Furthermore, in the anteroposterior radiographs of the wrist, the average value of radio ulnar inclination was $18.1^{\circ}$, and in the wrist profile radiograph, the average volar inclination of the radius was $6.7^{\circ}$. (Figure 2)

There was no difference in the association between physeal alterations with the age of onset of sports practice. However, there was a statistically significant difference in physis injury when the following variables were taken into account: years of training and hours of training per week. In these cases, the means were always higher in the group with radiographic change $(p<0.05)$. (Figures 3 and 4)

Regarding wrist pain, there was only a statistically significant difference regarding the weekly working hours, so that those who had wrist pain trained for more hours per week $(p=0.037)$. As for the relationship between wrist pain and years of training or age of onset of sports practice, there was no statistically significant difference.

Table 1. Mean values of active and passive arc of movement of the wrists.

\begin{tabular}{c|c|c|c|c|c|c|c|c}
\hline & $\begin{array}{c}\text { Active } \\
\text { Flexion }\end{array}$ & $\begin{array}{c}\text { Passive } \\
\text { Flexion }\end{array}$ & $\begin{array}{c}\text { Active } \\
\text { Extension }\end{array}$ & $\begin{array}{c}\text { Passive } \\
\text { Extension }\end{array}$ & $\begin{array}{c}\text { Active } \\
\text { radial } \\
\text { deviation }\end{array}$ & $\begin{array}{c}\text { Passive } \\
\text { radial } \\
\text { deviation }\end{array}$ & $\begin{array}{c}\text { Active } \\
\text { ulnar } \\
\text { deviation }\end{array}$ & $\begin{array}{c}\text { Passive } \\
\text { ulnar } \\
\text { deviation }\end{array}$ \\
\hline $\begin{array}{c}\text { Right } \\
\text { wrist }\end{array}$ & $66^{\circ}$ & $86.9^{\circ}$ & $59.1^{\circ}$ & $76.7^{\circ}$ & $22.3^{\circ}$ & $34.1^{\circ}$ & $35.6^{\circ}$ & $48.7^{\circ}$ \\
\hline $\begin{array}{c}\text { Left } \\
\text { wrist }\end{array}$ & $68.5^{\circ}$ & $85.8^{\circ}$ & $57.3^{\circ}$ & $74^{\circ}$ & $26.2^{\circ}$ & $36.8^{\circ}$ & $34.3^{\circ}$ & $48.9^{\circ}$ \\
\hline
\end{tabular}

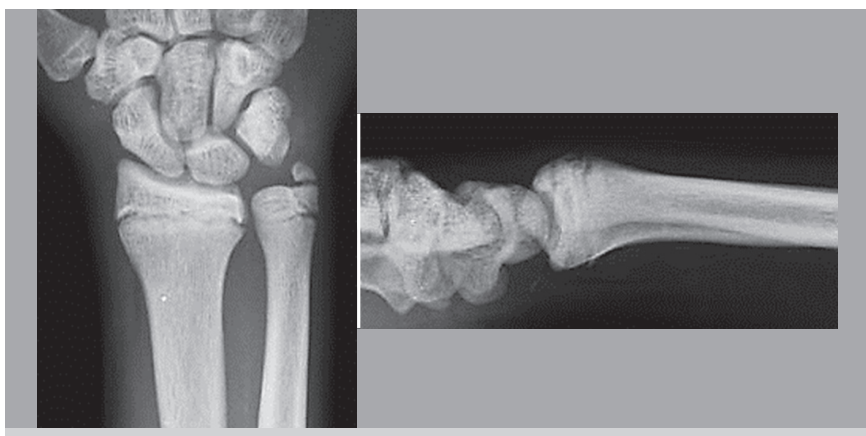

Figure 1. Front and profile $x$-ray of the right wrist of a young athlete with complain of wrist pain. Observe the enlargement of the distal physis of the radius and ulna and blurring of the radiolucent physis area. ${ }^{11}$

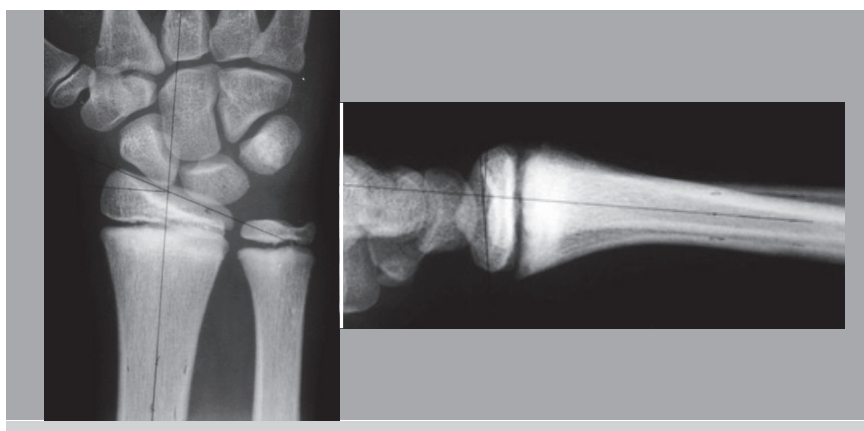

Figure 2. Front and profile $x$-ray of the left wrist of a young athlete without complain of wrist pain Observe the marks at ulnar $\left(20^{\circ}\right)$ and radial $\left(9^{\circ}\right)$ inclinations, respectively. 
Assessing the range of motion of the wrists, we observed a statistically significant decrease in passive Extension and active and passive radial deviation in cases where the appearance of the radial physis was altered $(p<0.05$, Table 2$)$.

Regarding the analysis of the ulnar and volar inclination angles radio on $\mathrm{x}$-rays, it was found that those with wrist pain had a higher average ulnar inclination of the radius $\left(19.1^{\circ}\right)$ than those who had no pain $\left(16.2^{\circ}\right)$, with $p=0.021$. We found a trend for increased volar inclination of the radius in patients reporting wrist pain, but without statistical significance $\left(7.8^{\circ}\right.$ in gymnasts

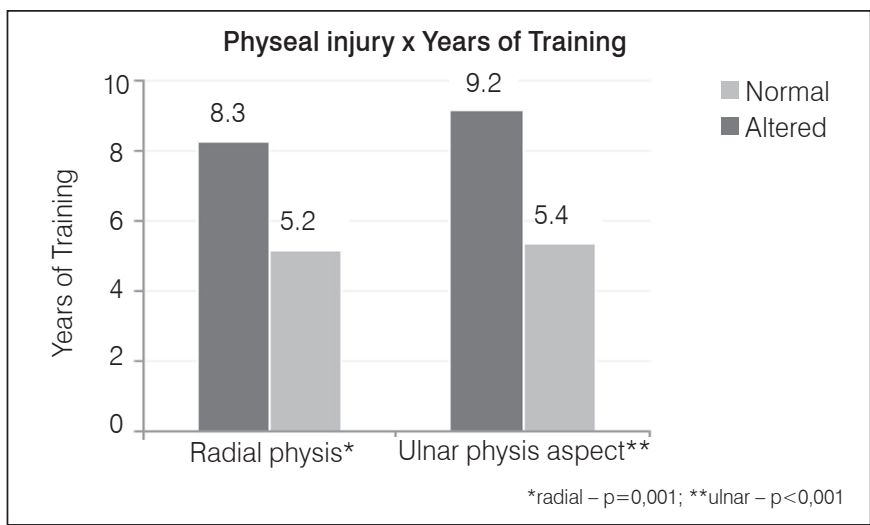

Figure 3. Relationship between radial and ulnar distal physeal injury and numbers of training years.

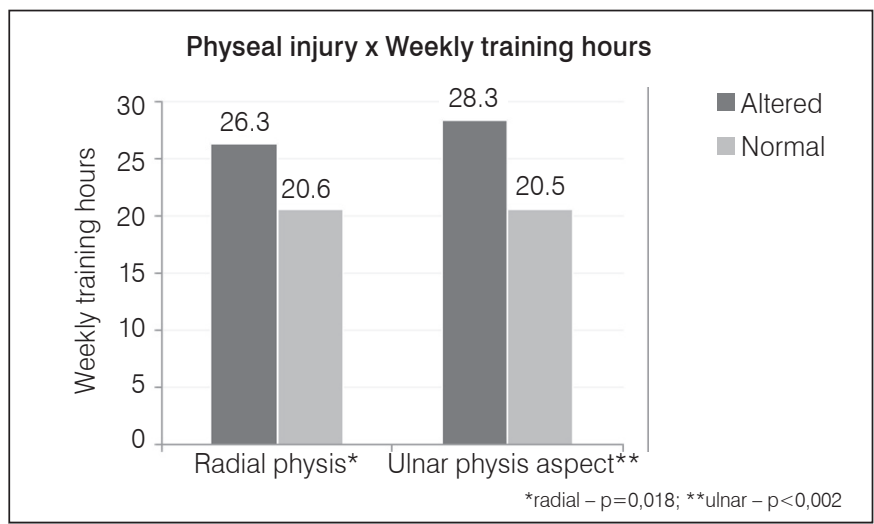

Figure 4. Relationship between radial and ulnar distal physeal injury and weekly training hours.

Table 2. Relationship between radial physis aspect and arc of movement.

\begin{tabular}{|c|c|c|c|c|c|c|}
\hline Physis aspect & Radius Distal & Mean & $\begin{array}{l}\text { Standard } \\
\text { deviation }\end{array}$ & $\mathrm{N}$ & IC & $p$-value \\
\hline \multirow{2}{*}{ Active flexion } & Altered & 67.2 & 9.8 & 39 & 3.1 & 0.187 \\
\hline & Normal & 72.4 & 12.1 & 18 & 5.6 & \\
\hline \multirow{2}{*}{ Passive flexion } & Altered & 85.4 & 13.1 & 39 & 4.1 & 0.103 \\
\hline & Normal & 90.8 & 11.8 & 18 & 5.5 & \\
\hline \multirow[b]{2}{*}{ Active extension } & Altered & 59.4 & 9.2 & 40 & 2.9 & 0.103 \\
\hline & Normal & 62.8 & 7.8 & 18 & 3.6 & \\
\hline \multirow{2}{*}{ Passive extension } & Altered & 73.8 & 9.2 & 39 & 2.9 & $<0.001$ \\
\hline & Normal & 85.3 & 7.1 & 18 & 3.3 & \\
\hline \multirow{2}{*}{$\begin{array}{c}\text { Active radial } \\
\text { deviation }\end{array}$} & Altered & 22.5 & 5.6 & 35 & 1.9 & $<0.001$ \\
\hline & Normal & 28.7 & 5.4 & 18 & 2.5 & \\
\hline \multirow{2}{*}{$\begin{array}{c}\text { Passive radial } \\
\text { deviation }\end{array}$} & Altered & 33.3 & 6.8 & 35 & 2.3 & $<0.001$ \\
\hline & Normal & 43.0 & 5.7 & 18 & 2.6 & \\
\hline \multirow{2}{*}{$\begin{array}{c}\text { Active ulnar } \\
\text { deviation }\end{array}$} & Altered & 36.5 & 5.2 & 35 & 1.7 & 0.566 \\
\hline & Normal & 35.5 & 5.4 & 18 & 2.5 & \\
\hline \multirow{2}{*}{$\begin{array}{l}\text { Passive ulnar } \\
\text { deviation }\end{array}$} & Altered & 49.8 & 5.1 & 35 & 1.7 & 0.831 \\
\hline & Normal & 49.7 & 7.8 & 18 & 3.6 & \\
\hline
\end{tabular}

with pain, $4.3^{\circ}$ in those without pain, $p=0.067$ ). There was no relationship between distal physeal injury of the radius and wrist pain $(p=0.493)$ and distal physeal injury of the ulna and wrist pain $(p=0.455)$, which shows them to be independent variables.

\section{DISCUSSION}

The increasing competitiveness and technical level in gymnastics are taking every time younger children to intense training routine aiming performance and high yield. Much has been discussed in the literature on the implications of these activities in the immature skeleton. Overload on the wrist of these athletes can become a threatening factor for their career, and can lead to harmful future consequences.

Studies show that the age of onset of this sport ranges from 3 to 12 years old, an approximate average of 5 and 7 years old, ${ }^{7,12,13}$ which is in line with the mean age found in this study, of 6 years old on average (range, 4 to 9 years). There were no studies mentioning the time elapsed since the start of training. As for the training intensity, in terms of weekly working hours, the literature shows that elite gymnasts often train on average $27-36 \mathrm{~h}$ per week, ${ }^{9,12,13}$ higher than average in this study (25.7h per week). In a recent systematic review, Kox et al., ${ }^{3}$ in 2015, observed a prevalence of wrist pain in young athletes of $32-73 \%$, narrowing to $56-67 \%$ in best quality studies. ${ }^{7.8}$ Very high numbers that can reach $82 \%$, as in the present study. The correlation of pain with clinical findings and possible outcomes remains unclear.

DiFiori et al. ${ }^{7}$ observed in a study with 59 gymnasts that the most important factors associated with wrist pain were high technical level, older athletes with more years of training, while in this study it was found that there are statistically significant only for wrist pain and increased weekly working hours. In the same study, as in others, an association between wrist pain and radiographs with physeal injury has been described. ${ }^{5-9,14-16}$ Unlike the present study, in which there was no significant association between injury in the distal physis of the radius or ulna and wrist pain.

The subjectivity of pain perception may be an obstacle when it comes to a pediatric athletic population. Nemeth et al. ${ }^{11}$ observed in a group of 68 Olympic level patients aged 6-13 years old, that the older ones (over 11 years old) have a better characterization of pain and understanding of its implications than the younger ones, mostly 6-8 year old. The authors warned about the risks that many of them understand pain as something to be overcome to improve performance, as if it were part of the training. In the present study, it was observed that, although there was wrist pain complaints in $82 \%$ of gymnasts, its intensity (according to the visual analog pain scale) showed an average of 3.7 points, a reason probably most athletes did not miss trainings. However, $47 \%$ of gymnasts reported that the pain limited their performance.

The sports modalities that worsened pain were the pommel horse $(82 \%)$, soil exercises (17\%) and parallel bars (12\%), probably because those are activities that increase the radio-carpal impact. DiFiori et al. ${ }^{6,7}$ also showed that the activities that were associated with wrist pain were soil exercises and pommel horse. ${ }^{14}$

During the physical examination, it was found that only five gymnasts had pain reproduced by palpation, similar to that observed by DiFiori et al., ${ }^{7}$ in which only two of the 33 athletes had it. Some authors noted some advantages in gymnastics practice in the pediatric population. In a study with 84 girls training up 
to $16 \mathrm{~h}$ per week, musculoskeletal benefits in the distal third of the forearm were observed in up to $66 \%$ of cases, such as improved strength and bone mass. ${ }^{2}$ In pre-pubertal children training at recreational and precompetitive levels, a better bone resistance was also observed..$^{17}$ This data demonstrated that there can be a fine line between sports practice leading to benefit or injuries caused by abuse.

Radiographic changes in the young gymnast's wrists began to be observed in the $80 s^{9,}{ }^{9,18,19}$ such as blurring or enlargement of the physeal plate, cystic alterations, epiphysis wedging and possible bone bars. Although well described, they depend on well-trained professionals for assessment, and may sometimes go unnoticed. The advent of magnetic resonance imaging could have brought greater sensitivity and specificity. 19,20

Regarding the association between physeal injury and number of weekly training hours or more training years, present in this study, another study found a significant relationship only for physeal injury and higher weekly workload, without significance for physeal injury and years of training. ${ }^{7}$

It was not found in the literature a comparison of radiographic changes of angular parameters and pain. In this study, we observed a significant increase in ulnar inclination $(p=0.021)$ and a tendency to increased volar inclination of the radius $(p=0.067)$ in patients with wrist pain. Probably, with a larger "n" we would be able to confirm this trend. It was also not find in the literature any relation between the limitation of the range of arc of movement of the wrist and radiographic changes, while in this study, we observed a significant reduction in passive Extension and active and passive radial deviation of physeal injured wrists. A limitation of this study was the low sample obtained and difficulty to obtain the athletes' adherence to the protocol. However, even with limited data, some correlations between pain, radiographic abnormalities, and other clinical aspects have been observed, obtaining significant relationship between physis injury and years of training, physis injury and hours of training per week, pain and training hours a week, physeal injury and change in range of motion, and finally, pain and alteration of the ulnar inclination angle of the radius.

The clinical outcome of these changes is not yet well established, as well as the implications of injuries in the development of young athletes, however, with the identification of risk factors and specific effects, many injuries could be prevented or treated in due time. Federations, parents, coaches and physicians should be aware that young gymnasts are at high risk for developing abuse injuries that cause pain and skeletal changes, which can lead to a number of complications that can be limiting and threaten promising careers.

\section{CONCLUSION}

We found in this study that $65 \%$ of gymnasts had physeal injury in the wrist and $82 \%$ had wrist pain, but there was no relationship between these variables. It was also possible to observe that the frequency of physeal injury was higher in athletes who had more years of training and higher weekly working hours. Wrist pain was more common in those with higher weekly working hours, there was a decrease of arc of movement in those with physeal alterations and increased ulnar inclination angle of the radius in those with wrist pain.

\section{ACKNOWLEDGEMENTS}

The authors are thankful to Dr. Antonio Carlos Costa and Dr. Ivan Chakkour for their support and encouragement in this study.

AUTHORS' CONTRIBUTION: Each author contributed individually and significantly to the development of the study. MRVG (0000-0001$6176-3325)^{*}$, JRDE (0000-0001-5146-8429)* YAA (0000-0003-0752-5128)* and DFF (0000-0002-3833-5397)* were the main contributors in drafting the manuscript and literature search. MRVG, JRPR (0000-0002-9745-9293)* and LHC (0000-0002-3548-1057)* collected and gathered clinical data. MRVG and YAA evaluated the data of the statistical analysis. MRVG, JRDE, YAA, DFF, JRPR and LHC analyzed and discussed the results, reviewed the manuscript and contributed to the intellectual concept of the study. ${ }^{*}$ ORCID (Open Research and Contributor ID).

\section{REFERENCES}

1. Stracciolini A, Casciano R, Friedman HL, Meehan WP 3rd, Micheli LJ. A closer look at overuse injuries in the pediatric athlete. Clin J Sport Med. 2015;25(1):30-5.

2. Burt LA, Ducher G, Naughton GA, Courteix D, Greene DA. Gymnastics participation is associated with skeletal benefits in the distal forearm: a 6-month study using peripheral Quantitative Computed Tomography. J Musculoskelet Neuronal Interact. 2013;13(4):395-404.

3. Kox LS, Kuijer PP, Kerkhoffs GM, Maas M, Frings-Dresen MH. Prevalence,incidence and risk factors for overuse injuries of the wrist in young athletes: a systematic review. Br J Sports Med. 2015;49(18):1189-96.

4. Caine D, DiFiori J, Maffulli N. Physeal injuries in children's and youth sports: reasons for concern? Br J Sports Med. 2006;40(9):749-60.

5. Caine D, Roy S, Singer KM, Broekhoff J. Stress changes of the distal radia growth plate. A radiographic survey and review of the literature. Am J Sports Med. 1992;20(3):290-8.

6. DiFiori JP, Puffer JC, Mandelbaum BR, Mar S. Factors associated with wrist pain in the young gymnast. Am J Sports Med. 1996;24(1):9-14.

7. DiFiori JP, Puffer JC, Aish B, Dorey F. Wrist pain, distal radial physeal injury, and ulnar variance in young gymnasts: does a relationship exist? Am J Sports Med. 2002;30(6):879-85

8. Chang CY, Shih C, Penn IW, Tiu CM, Chang T, Wu JJ. Wrist injuries in adolescent gymnasts of a Chinese opera school: radiographic survey. Radiology. 1995;195(3):861-4.

9. Roy S, Caine D, Singer KM. Stress changes of the distal radial epiphysis in young gymnasts. A report of twenty-one cases and a review of the literature. Am J Sports Med. 1985;13(5):301-8.

10. DiFiori JP, Caine DJ, Malina RM. Wrist pain, distal radial physeal injury,and ulnar variance in the young gymnast. Am J Sports Med. 2006;34(5):840-9.

11. Nemeth RL, von Baeyer CL, Rocha EM. Young gymnasts' understanding of

Acta Ortop Bras. 2016;24(4):204-7 sport-related pain: a contribution to prevention of injury. Child Care Health Dev. 2005:31(5):615-25.

12. De Smet L, Claessens A, Lefevre J, Beunen G. Gymnast wrist: an epidemiologic survey of ulnar variance and stress changes of the radial physis in elite female gymnasts. Am J Sports Med. 1994;22(6):846-50.

13. Malina RM, Baxter-Jones AD, Armstrong N, Beunen GP, Caine D, Daly RM, et al. Role of intensive training in the growth and maturation of artistic gymnasts. Sports Med. 2013;43(9):783-802.

14. DiFiori JP, Puffer JC, Aish B, Dorey F. Wrist pain in young gymnasts: frequency and effects upon training over 1 year. Clin J Sport Med. 2002;12(6):348-53.

15. Albanese SA, Palmer AK, Kerr DR, Carpenter CW, Lisi D, Levinsohn EM Wrist pain and distal growth plate closure of the radius in gymnasts. J Pediatr Orthop. 1989;9(1):23-8.

16. Liebling MS, Berdon WE, Ruzal-Shapiro C, Levin TL, Roye D Jr, Wilkinson R. Gymnast's wrist (pseudorickets growth plate abnormality) in adolescent athletes: findings on plain films and MR imaging. AJR Am J Roentgenol. 1995;164(1):157-9.

17. Erlandson MC, Kontulainen SA, Baxter-Jones AD. Precompetitive and recreational gymnasts have greater bone density, mass, and estimated strength at the distal radius in young childhood. Osteoporos Int. 2011;22(1):75-84.

18. Read MT. Stress fractures of the distal radius in adolescent gymnasts. $\mathrm{Br} J$ Sports Med. 1981:15(4):272-6.

19. DiFiori JP, Mandelbaum BR. Wrist pain in a young gymnast: unusual radiographic findings and MRI evidence of growth plate injury. Med Sci Sports Exerc 1996;28(12):1453-8

20. Dwek JR, Cardoso F, Chung CB. MR imaging of overuse injuries in the skeletally immature gymnast: spectrum of soft-tissue and osseous lesions in the hand and wrist. Pediatr Radiol. 2009;39(12):1310-6. 